\title{
COLD WEATHER AND ISCHAEMIC HEART DISEASE
}

\author{
BY \\ GEOFFREY ROSE \\ Department of Epidemiology, London School of Hygiene and Tropical Medicine, University of London
}

It is well known that the incidence of ischaemic heart disease tends to be higher in winter than in summer. In England and Wales, for example, mortality from "arteriosclerotic heart disease" (ASHD:ISC 420) averages 50 per cent. more in midwinter than in mid-summer (Annual Reports of the Registrar General of England and Wales); and a similar swing has been reported for hospital admission rates (Wolff and White, 1926). It may however be objected that results of this kind could have been biased by diagnostic uncertainties, by competing causes of morbidity and mortality, and by the possibility that respiratory infections may cause increased illness or death in persons already suffering from heart disease.

\section{Present Investigation}

The validity of these criticisms was tested by an analysis of the seasonal distribution of cardiac infarctions in the Medical Research Council Trial of Long-term Anticoagulant Therapy (Medical Research Council, 1959, 1964). Entry to this trial depended on highly-specific Q-wave criteria of infarction, and the occurrence of re-infarction during the trial was also carefully defined. The seasonal pattern was similar for initial infarctions and re-infarctions, and the combined results are shown in the Table. The winter peak is at almost twice the level of the summer trough, and it can

TABLE

SEASONAL DISTRIBUTION OF INITIAL INFARCTIONS AND RE-INFARCTIONS IN MEDICAL RESEARCH COUNCIL TRIAL OF LONG-TERM ANTICOAGULANT THERAPY

\begin{tabular}{|c|c|c|}
\hline Months & & No. of Infarctions \\
\hline $\begin{array}{l}\text { January-February } \\
\text { March-April } \quad \ldots \\
\text { May-June } \quad \text {. } \\
\text { July-August } \\
\text { September-October } \\
\text { November-December }\end{array}$ & $\begin{array}{ll}\cdots & \cdots \\
\cdots & \cdots \\
\cdots & \cdots \\
\cdots & \cdots\end{array}$ & $\begin{array}{l}77 \\
69 \\
50 \\
71 \\
89 \\
96\end{array}$ \\
\hline
\end{tabular}

therefore reasonably be presumed that the seasonal pattern in national mortality rates reflects true changes in the incidence of cardiac infarction.

Examination of ASHD mortality for different years reveals that the winter excess varies considerably from one year to another, with a maximum rise to 70 per cent. above the summer level and a minimum rise of less than 20 per cent. This is largely due to irregular fluctuations in the number of winter deaths, the trend for summer deaths being very smooth (Fig. 1).

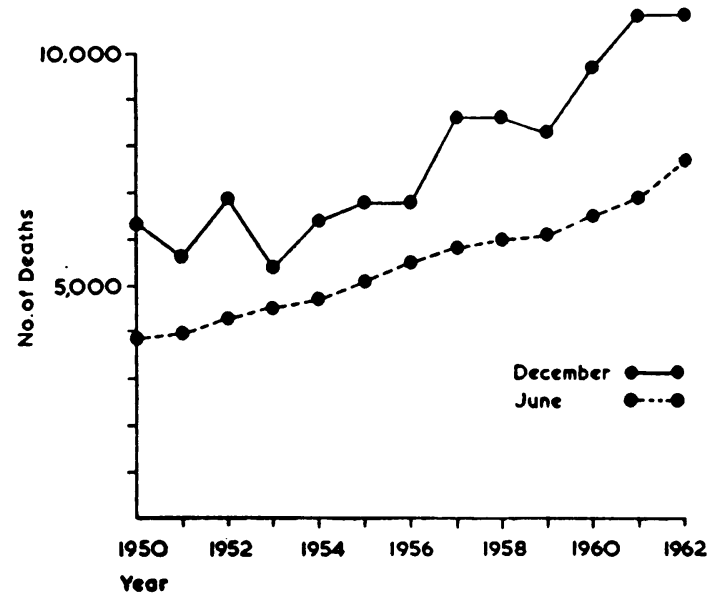

Fig. 1.-Numbers of deaths from ASHD (ISC 420) in England and Wales in June and December, 1950 to 62 .

The effect of the weather on mortality may be assessed by the correlation between the mortality excess of individual winters and a suitable measure of the abnormality of the weather in the corresponding winters. As an index of mortality excess, one may take the ratio of the number of deaths from ASHD in December of the year in question to the number of deaths from ASHD in the corresponding June. This ratio is independent of the absolute level 
of mortality in a particular year, so that comparisons covering a period of years are not disturbed by the strong secular trend. The temperature deviation of each winter has been measured by the ratio of the mean temperature $\left({ }^{\circ} \mathrm{F}\right.$.) at Kew (London) in December to the mean temperature in the corresponding June. A period of 13 years (1950 to 62) was studied and the results are illustrated in Fig. 2. The association is remarkably close: the correlation coefficients between the December mortality excess and the temperature index are -0.946 for males and -0.882 for females. This suggests an association specifically with the weather, since the statistical method used excludes any systematic seasonal trends unconnected with the particular weather at the time.

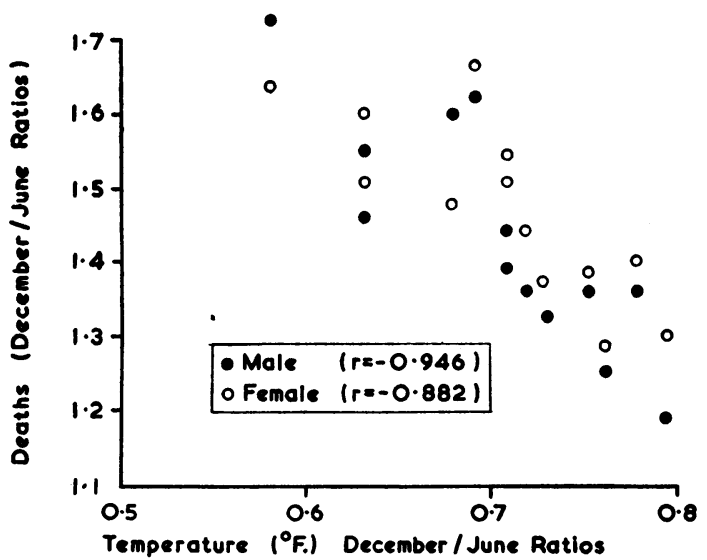

FIG. 2.-Relation between winter excess mortality from ASHD (ratio of December deaths to June deaths) and coldness (ratio of December mean temperature, ${ }^{\circ} \mathrm{F}$., to June mean temperature), 1950 to 62.

The correlation between ASHD mortality and air pollution was studied in a similar way, using the ratio of the maximum particulate pollution $\left(\mathrm{mg} . / \mathrm{m}^{3}\right)$ at Kew in December to the pollution in the corresponding June. It is clear from Fig. 3 that the association is much weaker than with coldness, the correlation coefficients being +0.399 (males) and +0.091 (females). For rainfall (December/June ratios) the association is weaker still, the correlation coefficients being $+\mathbf{0 . 2 8 9}$ for males and $+\mathbf{0 . 0 9 1}$ for females.

It is of much practical interest to know whether the adverse effect of coldness on ischaemic heart disease mortality begins to operate only below a certain critical temperature, or whether it is a matter of "the warmer the better, the colder the worse". This has been studied by analysing the relation between ASHD mortality and the mean temperature in each of the individual months of the period 1958 to 62

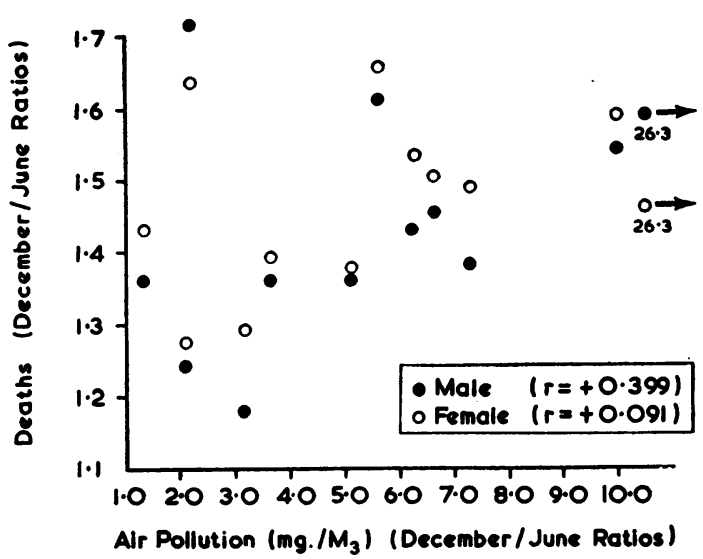

FIG. 3.-Relation between winter excess mortality from ASHD (ratio of December deaths to June deaths) and air pollution (ratio of December maximum pollution, $\mathrm{mg}$./m.', to June maximum pollution), 1950 to 62.

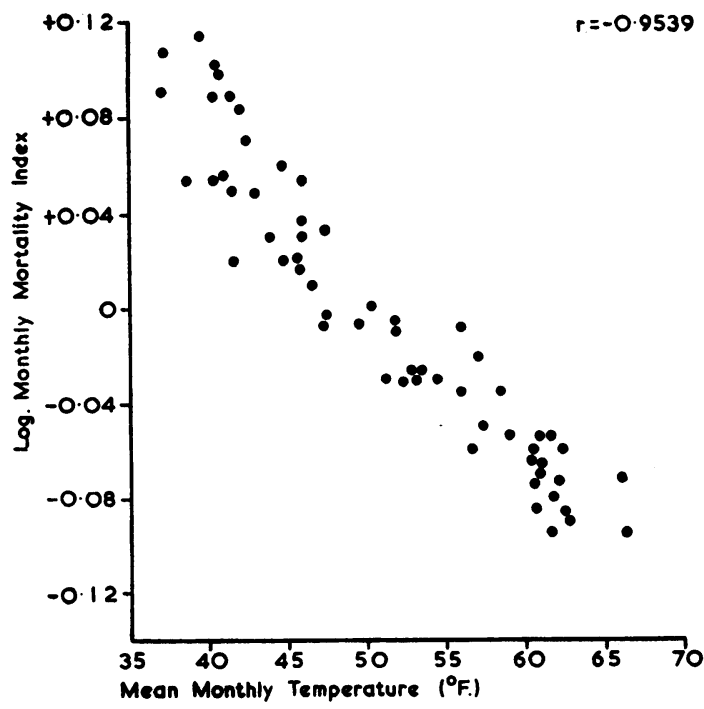

Fig. 4.-Relation between "log. monthly mortality index" for ASHD (males) and mean temperature $\left({ }^{\circ} F\right.$.) for each month of the period 1958 to 62 .

(Fig. 4). Mortality has been expressed as a "log monthly mortality index", which is the ratio of the mean daily deaths for a particular month to the mean daily deaths for the corresponding year, expressed logarithmically. This index is unaffected by secular trends or by the varying number of days in different months. It can be seen that over the whole of the observed range a rise in mean monthly temperature is associated with a fall in mortality, although the 
strength of the effect diminishes exponentially. The variation in temperature accounts for practically the whole of the variation in the monthly mortality indices, the correlation coefficient being -0.954.

Ischaemic heart disease is the leading cause of death in Great Britain, and any factor that influences it may affect the lives of large numbers of people. By relating the results in Fig. 2 to current mortality rates, it may be estimated that at the end of a cold December approximately 2,500 people will have died of ischaemic heart disease who might have been alive had the month been milder.

Naturally such an adverse experience is unlikely to be repeated in successive months, partly because the weather will tend to change and partly because of the removal of those who were most susceptible to its effects. Compensating changes in the opposite direction may perhaps tend to occur.

However, the number of persons dying of ischaemic heart disease in a cold year who might have survived to the end of a warm year can be estimated indirectly as follows. A smooth curve was fitted by eye to the annual numbers of deaths for the period 1950-62. In an unusually cold year (1958) the number of deaths from ASHD was about 2,500 above the expected level, but in milder years (e.g. 1953, 1957, 1959) the number was about one thousand below the expected level. It seems likely then that at the end of a cold year 2,500 to 3,500 people will have died of ischaemic heart disease who might still have been alive had the year been warmer.

\section{Discussion}

These results are in general agreement with those of Boyd (1960), although the present study reveals a closer association. Many hospital studies have shown a winter peak in admissions for cardiac infarction (e.g. Wolff and White, 1926; Bean and Mills, 1938; Gorbatow, 1961), but there are exceptions (Mintz and Katz, 1947; Master and Jaffe, 1952; Holland, Spicer, and Wilson, 1961; Westlund, 1965; Fogel and Righthand, 1964); possibly the discrepancies are due to the complexity of the factors governing hospital admission, including competition from respiratory and other winter diseases. An association has been demonstrated within the United States between coronary mortality rates and the mean temperature of the locality (Moriyama and Herrington, 1938).

The very high correlations with coldness in the present study indicate that practically all of the short-term fluctuations in ischaemic heart disease mortality can be accounted for by temperature variations, and the closeness of the association strongly suggests that the relation is one of cause and effect. Some correlation with air pollution was bound to be observed, because of its association with coldness; but the association is clearly much weaker (Figs 2 and 3), and it seems that coldness is the important determining factor.

The mechanisms by which cold influences cardiac infarction must remain conjectural. The anginal subject who goes out on a cold morning may experience at once the effect on his heart, and it may be that the influence of cold on infarction is also a short-term one. On the other hand, Boyd (1960) found that mortality from "heart disease" in London did not correlate as closely with the temperature for the same week $(r-0.552)$ as with that for the previous week $(r-0.744)$, or even that of two weeks previously $(r-0.688)$. Similarly in the present study the correlations were very high despite the facts that they related to periods of one month and that temperature at one place (Kew) was being compared with mortality rates for the country as a whole. It may be then that there is a cumulative or a delayed effect of cold that operates over a period of a few weeks. The time interval could be assessed more directly by studying the association between temperature (or change in temperature) and the date of onset of infarction, rather than the date of registration of death.

The effect of cold might operate in many ways, including general body cooling, local skin cooling, cooling or altered humidity of inspired air, or change in personal habits. Investigation of possible mechanisms will have to include the effects of cold on habits such as eating and physical activity, as well as on other risk factors that are known to have seasonal trends, e.g. serum cholesterol (Thomas, Holljes, and Eisenberg, 1961) and blood pressure (Rose, 1961). In the meantime it may nevertheless be prudent to advise coronary patients to keep warm in winter.

\section{SUMMARY}

Mortality for ASHD in England and Wales shows a seasonal pattern similar to that for cases of proven cardiac infarction. The mid-winter peak ranges from 20 per cent. to as much as 70 per cent. above the mid-summer trough. The winter excess of deaths in any particular year is very highly correlated with coldness, but not to a significant degree with either air pollution or rainfall. A fall in mortality with rise in temperature is apparent over the whole of the observed temperature range, although the magnitude of the effect diminishes exponentially. It appears that changes in temperature are responsible for most of the short-term fluctuations in ischaemic heart disease mortality. 
The data on seasonal distribution of clinical cardiac infarction were made available by kind permission of the Working Party on Anticoagulant Therapy in Coronary Thrombosis to the Medical Research Council. I am grateful to Miss L. Jenkins, S.R.N., and Mrs E. Killick for help in computing.

\section{REFERENCES}

Bean, W. B., and Mills, C. A. (1938). Amer. Heart J., 16, 701.

Boyd, J. T. (1960). Brit. J. prev. soc. Med., 14, 123.

Fogel, D. H., and Righthand, N. (1964). Brit. Heart J., $26,255$.

Gorbatow, O. (1961). Acta med. scand., Suppl. 364.
Holland, W. W., Spicer, C. C., and Wilson, J. M. G. (1961). Lancet, 2, 338.

Master, A. M., and Jaffe, H. L. (1952). J. Amer. med. Ass., 148, 794.

Medical Research Council (1959). Brit. med. J., 1, 803. (1964). Ibid., 2, 837.

Mintz, S. S., and Katz, L. N. (1947). Arch. intern. Med., 80, 205.

Moriyama, I. M., and Herrington, L. P. (1938). Amer. J. Hyg., 28, 423.

Rose, G. A. (1961). Nature (Lond.), 189, 235.

Thomas, C. B., Holljes, H. W. D., and Eisenberg, F. F. (1961). Ann. intern. Med., 54, 413.

Westlund, K. (1965). J. Oslo Cy Hosp., 15, 201.

Wolff, L., and White, P. D. (1926). Boston med. surg. J., $195,13$. 